\title{
Industry Perspective on OA
}

\author{
Ed. E. C. Margerrison, PhD
}

Received: 31 August 2011/Accepted: 12 December 2011/Published online: 23 February 2012

(C) The Author(s) 2012. This article is published with open access at Springerlink.com

\section{Introduction}

The progressive degenerative changes associated with osteoarthritis (OA) can arise from age-related chronic degeneration or can be triggered by traumatic changes in the articular cartilage and/or subchondral bone. Traditionally, the orthopaedics industry has intervened in this disease progression only in the latter stages with joint replacements, but the picture has been changing over the last few years with the development of novel products and techniques. In addition to arthroplasty, the orthopaedics industry is now considering three alternative points of intervention in the disease, namely: (1) pain treatment; (2) disease progression; and (3) treatment of cartilage and osteochondral trauma, all essentially allowing for preservation of the joint. Whilst joint arthroplasty remains an extremely successful treatment option, a realistic aim of the healthcare industry must be to prevent disease progression, through early intervention allowing for a more complete return to function for patients.

\section{Industry Innovations in Pain Management in OA}

Treatment of OA pain has been largely the domain of pharmaceutical companies, but over the last few years, a number of orthopaedic players have developed intraarticular injections of hyaluronic acid (HA) for treatment of pain. Adoption of this technology has suffered to some extent due to the requirement for a course of multiple injections and reports of pseudosepsis. Newer formulations are now becoming available that require only a single injection, with pain relief lasting for several months and no apparent incidence of pseudosepsis [3].

\footnotetext{
E. E. C. Margerrison $\mathrm{PhD}(\triangle)$

Orthobiologics R\&D,

Zimmer Inc., Austin, TX, USA

e-mail: ed.margerrison@zimmer.com
}

The provision of such HA products by orthopaedic companies is a radical change from the traditional "metal and plastic" of previous years, and a natural extension to this will be for companies to provide similar products that can slow or arrest disease development. Although no such products are currently available, it is an area of active research.

\section{Industry Innovations in Cartilage Repair}

Perhaps the most significant advances in OA by orthopaedic companies have resulted from approaches to the surgical treatment of chondral and osteochondral lesions or cartilage restoration. A variety of approaches exist for treating these lesions, mostly using autograft tissue (e.g., OATS or autologous chondrocyte implantation procedures) or allograft tissue, but each has limitations. Zimmer has recently introduced two new implants to provide a therapeutic cartilage repair whilst avoiding some of the pitfalls of other techniques: DeNovo NT ${ }^{\circledR}$ Natural Tissue Graft is an allograft composed of particulated live juvenile cartilage containing viable chondrocytes. It has been well reported that the metabolic activity of juvenile cells is significantly higher than adult cells [1], and consequently, it might be expected that the repair may be improved over other methods. To date, approximately 2,500 cases have been conducted with this allograft, and initial clinical results appear extremely promising [2] through 2 years of follow-up.

Osteochondral allografts have provided a good option for repair for over three decades, but have been reported to induce immune responses to the graft, leading to prolonged inflammatory reactions, cartilage degeneration and delayed graft incorporation. A recently introduced product (Chondrofix ${ }^{\circledR}$ Osteochondral Allograft) seems to be less prone to these issues owing to the removal of lipids and other cell debris. Additionally, this product has the advantage of a 2-year shelf life whilst retaining all mechanical properties of native tissue. 
Clinical experience is still limited to date, but early indications are promising, and in preclinical studies, the implant has been shown to provide repair for a minimum of 18 months.

\section{Summary}

The intention of these newer implants is the treatment of cartilage lesions as soon as they become symptomatic and returning the patient to a level of function as high as that achieved prior to injury. As technology advances, we might expect to see the emergence of disease-modifying treatments for OA, further improvements in pain medication and also the emergence of genuinely efficacious tissue-engineered chondral repair products. A number of these are currently in phase 3 clinical studies.

Disclosures The author certifies that he or she has or may receive payments or benefits from a commercial entity related to this work.
Open Access This article is distributed under the terms of the Creative Commons Attribution Noncommercial License which permits any noncommercial use, distribution, and reproduction in any medium, provided the original author(s) and source are credited.

\section{References}

1. Adkisson HD 4th, Martin JA, Amendola RL, Milliman C, Mauch KA, Katwal AB, Seyedin M, Amendola A, Streeter PR, Buckwalter JA. The potential of human allogeneic juvenile chondrocytes for restoration of articular cartilage.. Am J Sports Med 2010;38:1324-33.

2. Farr J II, Yao JQ. Chondral defect repair with particulated juvenile cartilage allograft. Cartilage 2011;2:346-353.

3. Strand, V., et al. A multicenter, randomized controlled trial comparing a single intra-articular injection of Gel-200, a new cross-linked formulation of hyaluronic acid, to phosphate buffered saline for treatment of osteoarthritis of the knee. Osteoarthritis and Cartilage 2011 (in press). 